\title{
EMPREENDEDORES IMIGRANTES DENTRO OU FORA DO ENCLAVE ÉTNICO: UM ESTUDO EXPLORATÓRIO
}

Roberto Pessoa De Queiroz Falcão ${ }^{1}$

Eduardo $\mathrm{Cruz}^{2}$

Irene Ciccarino ${ }^{1}$

Fernando Petri ${ }^{3}$

\footnotetext{
${ }^{1}$ Pontifícia Universidade Católica do Rio de Janeiro (PUC-Rio) - IAG

${ }^{2}$ Departamento de Empreendedorismo e Gestão / Faculdade de Administração e Ciências Contábeis / Universidade Federal Fluminense

${ }^{3}$ Universidade Federal Fluminense
} 


\section{EMPREENDEDORES IMIGRANTES DENTRO OU FORA DO ENCLAVE ÉTNICO: UM ESTUDO EXPLORATÓRIO}

Resumo: O artigo examina a relação entre empreendedores imigrantes e seus enclaves étnicos, influenciada pela afiliação cultural com suas comunidades e pela motivação empreendedora (por oportunidade ou necessidade). Enquanto alguns empresários de origem étnica decidem concentrar seus negócios em suas próprias comunidades, outros escolhem o mercado local como foco de atuação. Portanto, o artigo discute causas plausíveis e implicações dessas escolhas, com base em estudos de caso de seis empresários brasileiros estabelecidos no Sul da Flórida. Os empresários que se concentram em enclaves, desenvolvem (ou se beneficiam) das vantagens competitivas de explorar o nicho étnico. Ao contrário disso, empresários que se concentram nos mercados locais rejeitam seus próprios compatriotas e sua cultura, porém, são capazes de explorar uma gama mais ampla de clientes. As descobertas das entrevistas são confrontadas com teorias sobre o empreendedorismo étnico e de imigrantes.

Palavras-chave: Empreendedorismo imigrante. Enclave étnico. Rede de imigrantes

\section{Introdução}

O empreendedorismo vem ganhando espaço nas discussões quanto o debate envolve aspectos econômicos da sobrevivência de grupos étnicos. No contexto das oportunidades de negócio apresentadas a esses empresários, destaca-se uma nítida distinção entre as ações dentro ou fora do enclave étnico no qual estes estão inseridos (Zhou, 2004). O intuito desse artigo, portanto, é o de promover uma discussão sobre fatores que levam a alguns empresários imigrantes a se concentrarem em ações mercadológicas enfocadas no enclave étnico ou, como alternativa, voltadas para o mercado local. Assim, espera-se contribuir para a discussão sobre o tema do empreendedorismo étnico e de imigrantes, através de uma análise de fatores que afetam as decisões de mercado em relação aos objetivos de seus clientes.

Foram entrevistados seis empresários brasileiros estabelecidos em regiões de grande imigração brasileira no Sul da Flórida, o que promoveu um contexto de pesquisa pouco usual, haja vista que nos estudos do empreendedorismo imigrante e étnicos norte-americanos e europeus, há um protagonismo de etnias hispânicas e asiáticas (a exemplo de Barret, Jones, \& McEvoy, 1996; Portes \& Zhou, 1992; Rath \& Kloosterman, 2000. O recente fenômeno da
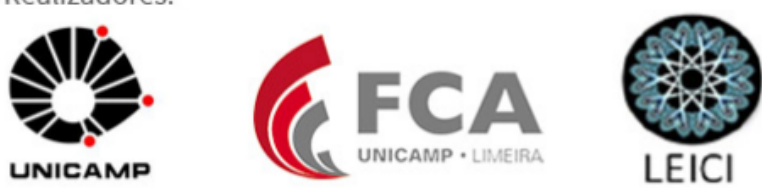
imigração brasileira (Sales, 1999), apresenta um conjunto de lacunas de pesquisa, relativas ao comportamento desse grupo em relação às tradicionais etnias estudadas em pesquisas estrangeiras.

Empreendedores imigrantes provenientes de países menos desenvolvidos têm características diferentes das populações locais. O seu mix de capitais humano, social e econômico (Bourdieu, 1986; Coleman, 1998) geram produtos distintos, permitindo-lhes ver de forma diferente as oportunidades e os recursos étnicos (Rath \& Kloosterman, 2000). Assim sendo, como as empresas de imigrantes operam tanto dentro quanto fora dos enclaves, algumas questões são investigadas: (i) qual é a influência do relacionamento do empreendedor com seu enclave étnico na escolha do seu público-alvo? (ii) a afiliação cultural é um fator chave nessa decisão? (iii) qual é a influência da motivação empresarial (oportunidade ou necessidade) nessa decisão? Esses questionamentos formam as três dimensões analisadas no artigo.

Foi utilizada como metodologia o estudo de caso exploratório, por meio da seleção de casos ilustrativos de empresários brasileiros. A apresentação dos casos, bem como a sua análise, seguiu os procedimentos de Eisenhardt (1989), dado que segundo o autor, estudos de caso podem revelar novos aspectos da teoria. No projeto de pesquisa original, o qual evidenciou o fenômeno migratório brasileiro no Sul da Flórida, foram realizadas um total de 90 entrevistas, sendo selecionadas seis das mais representativas, analisadas com auxílio do software 'Atlas.ti', com o objetivo de agrupar as descobertas dentro das categorias. O artigo ainda considera questões de adaptação que emergiram das entrevistas, tais quais: se os empresários estão confortáveis com a cultura do país anfitrião? Ou, se falam fluentemente a língua do país anfitrião? Dessa forma, são apresentadas implicações teóricas e de cunho prático, as quais são discutidas na seção de considerações finais.

\section{Imigrantes, enclaves étnicos, assimilação e oportunidades de negócios}

Enquanto a imprensa internacional exibe a questão de políticas de imigração mais criteriosas, impactando ainda mais a discriminação étnica, no contexto das sociedades norte-americanas e européias, os empresários imigrantes bem sucedidos geram bilhões de dólares em riqueza, que circula dentro de enclaves étnicos (Portes \& Zhou, 1992).

A definição de um enclave étnico está intimamente relacionada com a concentração de um determinado grupo étnico, e com a configuração de uma rede intrincada de estabelecimentos comerciais e habitações. De acordo com Zhou (2004), "enclaves étnicos" promovem também mercados de trabalho étnicos, nos quais os imigrantes têm benefícios e oportunidades para progredir socialmente. São instituições culturalmente unidas, que mantêm laços de solidariedade e confiança, através do seu "capital social" (Bourdieu, 1986; Coleman, 1998). Em suma, as principais características da economia do enclave são a "co-etnicidade" dos
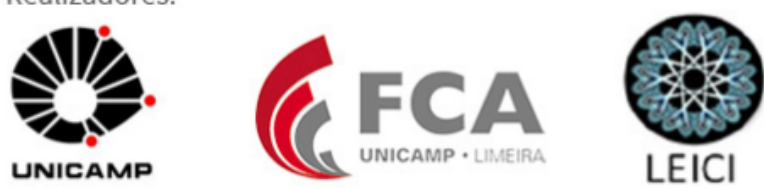
trabalhadores e empresários, bem como a concentração geográfica das empresas étnicas. Tais enclaves étnicos têm a capacidade de reduzir as barreiras de imigração, enquanto ao mesmo tempo aumentam as oportunidades econômicas, formando redes de proteção que alavancam os ganhos gerados pelas empresas imigrantes (Drori, Honig, \& Wright, 2009). Além disso, eles tiram proveito de profissionais disponíveis legalmente ou informalmente, que aceitam salários baixos devido à sua vulnerabilidade social. Adicionalmente, esses enclaves promovem a disseminação de informações importantes a respeito de mercados, concorrência, fornecedores confiáveis ou melhores práticas comerciais. Essas comunidades também podem ajudar os empresários através de formas não tradicionais de aquisição de crédito, devido às relações de confiança estabelecidas - o guanxi em comunidades chinesas (Light, Bhachu, \& Karageorgis, 1993) - ou o sistema mexicano de crédito informal (Portes, 1997).

Redes de comércio transnacional e redes de varejo étnicas locais estão presentes nas mais diversas áreas metropolitanas em torno dos cinco continentes. Fluxos de idéias, mentes, capital e bens ocorrem diariamente, promovidos por sistemas de comunicação eficientes, transporte rápido e barato. Alguns desses fluxos atingem uma escala global. O impacto das redes de apoio aos imigrantes durante a fase de criação das empresas (Saxenian, 2007) é evidente nos enclaves. Isso foi apontado por vários autores, como Portes e Zhou (1992), Barret, Jones e McEvoy (1996) e Rath e Kloosterman (2000).

Embora alguns empresários imigrantes tenham baixo capital humano, eles conseguem iniciar suas pequenas empresas como uma forma de auto-emprego ou mera sobrevivência (Aldrich \& Waldinger, 1990). No entanto, sua afiliação co-étnica e as próprias comunidades podem promover efeitos benéficos (Portes \& Zhou, 1992), enquanto são explorados os nichos nos quais eles possuem vantagens competitivas (Porter, 1989). Portes e Zhou (1992), ao pesquisarem chineses, dominicanos e cubanos, postularam que o empreendedorismo étnico é uma forma alternativa para imigrantes saírem de uma situação econômica estagnada. Portanto, os pequenos empresários que trabalham intensivamente, promovem a mobilidade econômica. De acordo com Zhou (2004), membros de enclaves étnicos estão culturalmente unidos, mantendo laços de solidariedade e confiança, a chamada "confiança limitada". Esses empreendedores tipicamente se ocupam de mercados de nicho específicos. Embora não exclusivamente, eles poderiam ser empresários que experimentaram trajetórias de imigração irregular e possuem habilidades lingüísticas limitadas, que aumentam as barreiras de comunicação. Alguns entram em países de acolhimento com vistos de turista ou de estudante. No outro extremo, estão os que entram legalmente no país de acolhimento. Apesar de terem perspectivas de trabalho mais amplas, executivos expatriados, cidadãos com dupla cidadania ou migrantes com casamentos programados, também podem optar por atenderem ao mercado étnico, devido à menor concorrência configurada nessa arena.

Certos grupos étnicos, com base em relacionamentos previamente estabelecidos, decorrentes de vínculos de capital social (Coleman, 1998), também podem escolher destinos específicos

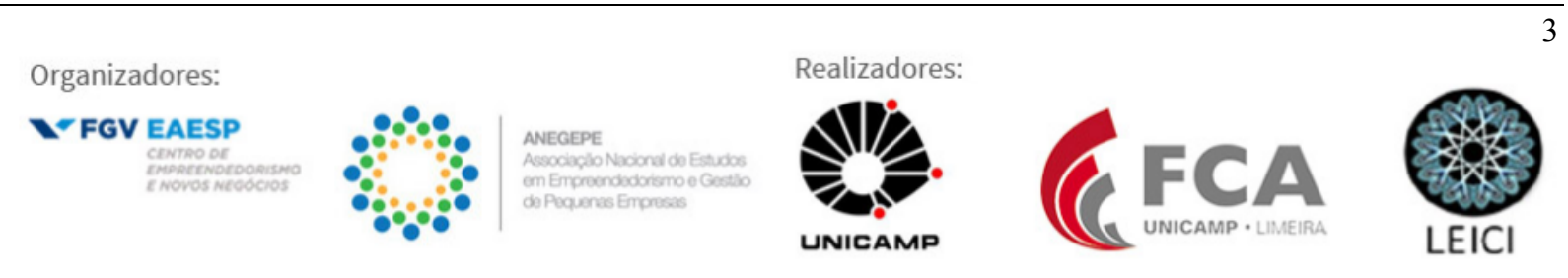


para se estabelecerem. Portes e Sensenbrenner (1993), enquanto discutem as particularidades da 'confiança limitada', concluem que co-étnicos que vivem no exterior se tornam mais conscientes de seus símbolos nacionais comuns. Eles promovem um apoio mútuo, bem como uma "rede de segurança". Historicamente, várias comunidades de imigrantes estabeleceram-se e dispersaram-se pelo mundo, embora as sociedades acolhedoras enxergassem esses grupos étnicos com ressalvas, o que gerou teorias de assimilação como da 'anglo-conformidade', 'melting-pot' e 'pluralidade cultural' (Gordon, 1961).

Zhou (2004) cita três orientações de mercado distintas, típicas dos empresários imigrantes: (i) o mercado de nicho étnico, que atende aos gostos e características específicas dos membros da comunidade étnica (por exemplo, vestuário, comida, música étnica); (ii) busca por oportunidades no mercado em geral que abordam demandas latentes não atendidos pelos empresários locais, geralmente em bairros pobres (por exemplo, farmácias, supermercados ou lojas de conveniência); (iii) venda de produtos exóticos para residentes locais (por exemplo, restaurantes de culinária étnica, lojas de decoração e estúdios de artes marciais).

A concentração espacial das populações étnicas e de imigrantes geralmente configura mercados robustos com demandas específicas. Além disso, algumas atividades que ocorrem dentro de enclaves étnicos podem ser invisíveis para os empresários locais, como empresas de alimentação étnica informal, lojas de roupas étnicas e empreiteiras de construção. Essas empresas garantem não apenas a sobrevivência diária dos imigrantes, como também uma possibilidade de ascensão social (Portes \& Zhou, 1992).

Os modelos explicativos sobre o empreendedorismo imigrante que trabalham dentro do enclave (por exemplo, Waldinger, 1993; Xie \& Gough, 2011) não explicam completamente por que certos empresários, do mesmo grupo étnico, seguem caminhos diferentes quando se esforçam para se distanciar de elementos que os associem às suas origens. Estes direcionam seus esforços à clientes de fora de seus enclaves, se aventurando em um mercado local mais abrangente e competitivo. A literatura existente assume que as escolhas dos empreendedores derivam de uma composição de sua própria personalidade (Filion, 2011) e as escolhas estratégicas das empresas. No entanto, ambas (escolhas estratégicas e empreendedoras) estão relacionados às suas características individuais (Barkham \& Gudgin, 2002). Muitos autores propõem pressupostos que ajudam a esclarecer oportunidades de mercado e decisões estratégicas. Roper (1998) seleciona, por exemplo, posições de mercado - foco de produto / mercado; características comerciais como educação, idade, experiência; públicos-alvo; condições de mercado, como o poder do cliente, os requisitos de capital e as provisões da força de trabalho. Carter (2000) ainda inclui: o gênero do empreendedor, a afiliação às organizações profissionais ou a experiência comercial anterior.

Avançando sobre esses pressupostos, o presente estudo observa o nível de afiliação às suas comunidades étnicas, seus públicos-alvo (clientes étnicos ou locais) e o tipo de orientação comercial empreendedora (por necessidade ou oportunidade). Esses pressupostos relacionados

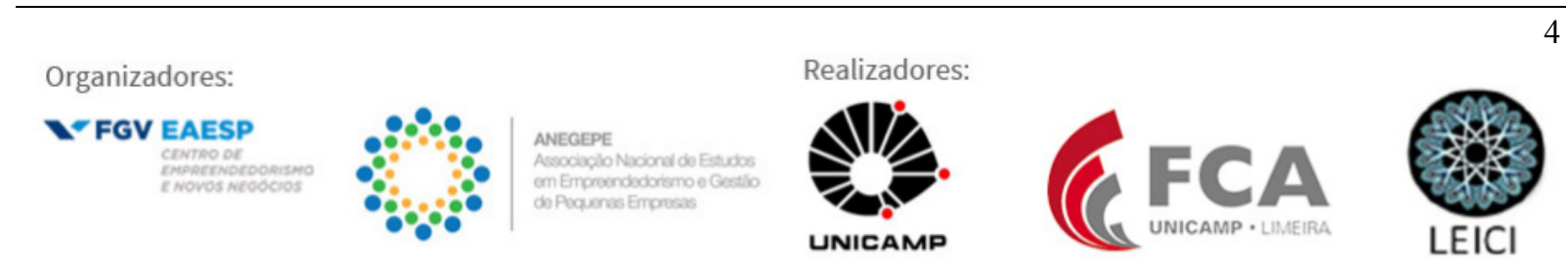


aos imigrantes e empresários étnicos foram originalmente associados a aspectos sociológicos da assimilação de imigrantes e suas ações empreendedoras (por exemplo, Portes \& Zhou, 1992). No entanto, é percebido que há mais do que simplesmente aspectos da assimilação envolvidos, o que é discutido mais adiante neste artigo. Ao examinarem o grupo étnico brasileiro no exterior, Cruz, Falcão e Barreto (2017a) evidenciaram ondas migratórias distintas com composições específicas de capitais humanos, sociais e econômicos, o que resultou em distintas estratégias de mercado. Alem disso, destacaram que alguns desses empresários demonstraram certa aversão à comunidade brasileira no exterior.

A literatura de empreendedorismo existente, nas últimas décadas, apresentou diferentes quadros conceituais para explicar os fatores que impulsionam a decisão da criação de empresas (Bolton \& Thompson, 2000; Burns, 2001). No entanto, um esquema classificatório particular tornou-se cada vez mais predominante - uma estrutura bifurcada proposta por Bögenhold (1987). O autor distinguiu dois tipos de empresários, aqueles impulsionados pelas necessidades econômicas e aqueles motivados por um desejo de auto-realização.

É muito discutido se os "empresários à margem da lei" são realmente movidos pela necessidade ou impulsionados pela oportunidade (Williams, 2009). Geralmente, os autores descrevem os empresários informais como movidos pela necessidade, o que configura estratégias de sobrevivência frente à ausência de opções alternativas (Castells \& Portes, 1989). Por outro lado, os movidos pela oportunidade são os empresários 'planejadores de negócios', que irão, provavelmente, focar em segmentos de mercado mais amplos. Não obstante, a literatura recente procurou estudar o que se entende por oportunidade empresarial (Casson \& Wadeson, 2007; Companys \& McMullen, 2007).

\section{Procedimentos metodológicos}

A principal estratégia de coleta de dados foi o uso de entrevistas em profundidade (Denzin \& Lincoln, 2011), todas conduzidas em português, com empresários brasileiros do sul da Flórida, estabelecidos nos arredores de Miami, na região de Pompano Beach (principal concentração brasileira). A área da pesquisa incluiu as cidades de Fort Lauderdale, Delray Beach, Deerfield Beach, Boca Raton, bem como o Condado de Miami Dade. Os pesquisadores seguiram um roteiro semi-estruturado (Creswell, 2013), que continha questões sócio-demográficas e de negócios. As entrevistas foram realizadas nas instalações ou nas casas dos empresários. Anotações e observações de campo complementaram a coleta de dados. As entrevistas duraram de 40 a 60 minutos, gravadas usando um tablete, sendo elas transcritas integralmente. Seu objetivo foi o de compreender as trajetórias empresariais dos imigrantes, perguntando como se deu o início de seus negócios, as motivações para sua criação e seu público-alvo. Assim, os pesquisadores desvendaram suas histórias de vida ao chegarem nos EUA. Além disso, eles procuraram indícios de sua afiliação com a comunidade

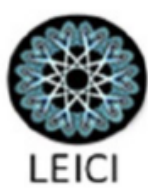


e escolha estratégica. Ao analisar os dados usando o software 'Atlas.ti', os pesquisadores propuseram categorias que emergentes dos discursos, contrastando-as com o quadro teórico do referencial. Por sua natureza qualitativa e exploratória, o objetivo do estudo não foi o de quantificar com precisão o número de empresas brasileiras ou testar estatisticamente quaisquer hipóteses. Seis entrevistas representativas de empreendedores foram selecionadas de uma amostra original de 90 entrevistas com empresários brasileiros com sede na Flórida, realizadas entre 2012 e 2015. Dos seis empresários selecionados, três deles adotaram como alvo o enclave brasileiro e outros três serviram no mercado local, sem nenhuma distinção de etnia, no tocante a seu público-alvo. Os pesquisadores seguiram os procedimentos de Eisenhardt (1989) ao apresentarem os casos e analisar os dados coletados, visando fazer proposições. O script de entrevista incluiu o levantamento de dados sócios demográfícos e profissionais dos empreendedores, informações sobre a decisão de deixar o Brasil. Já a Tabela 1 mostra a informação geral dos entrevistados selecionados para o estudo de caso e análise.

Tabela 1 - Informações dos entrevistados

\begin{tabular}{c|c|c|c|c|c|c|c}
\hline Entrevistado & Alvo & Atividade & Local & Sexo & Idade & $\begin{array}{c}\text { Anos nos } \\
\text { EUA }\end{array}$ & $\begin{array}{c}\text { Experiência } \\
\text { anterior nos EUA }\end{array}$ \\
\hline A & Enclave & Padaria e confeitaria & Boca Raton & $\mathrm{M}$ & 55 & 28 & Semelhante \\
\hline B & Enclave & Contabilidade & Pompano & $\mathrm{M}$ & 53 & 23 & Diferente \\
\hline C & Enclave & Coaching e consultoria & Boca Raton & $\mathrm{M}$ & 48 & 14 & Diferente \\
\hline D & Geral & Limpeza e limpeza & Delray & $\mathrm{F}$ & 52 & 15 & Semelhante \\
\hline E & Geral & Limpeza e reparação de roupa & Pompano & $\mathrm{F}$ & 67 & 20 & Diferente \\
\hline F & Geral & TI & Doral & M & 61 & 22 & Semelhante \\
\hline
\end{tabular}

A seção a seguir apresenta um resumo dos relatos das entrevistas. A violência, a instabilidade econômica, a desorganização institucional, a burocracia, a falta de perspectivas para o crescimento da carreira e a limitação do progresso pessoal ligados ao conforto e à qualidade de vida foram os motivos da emigração, que mais emergiram nas entrevistas.

(Casson \& Wadeson, 2007; Companys \& McMullen, 2007).

\section{Apresentação dos casos observados}

O empreendedor "A" tem uma padaria na Flórida. Trabalhava como operário em uma fábrica de multinacional do ramo farmacêutico no Brasil, mas sonhava em viver nos EUA. Sua principal motivação para deixar o Brasil foi a paixão pela cultura americana e a falta oportunidade de crescimento profissional ou financeiro. Um colega de trabalho fez contato com outro amigo que morava na América e o ex-gerente da fábrica escreveu uma carta de confirmação de vínculo de trabalho, conseguindo um visto de turista. Morou no Texas e Nova York antes de se instalar na Flórida, "muito melhor devido ao seu clima brasileiro". Não tinha

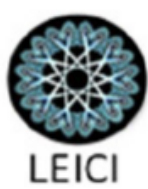


intenção de empreender, queria conseguir um emprego regular e ganhar dinheiro. Além disso, não tinha conhecimento sobre administração de empresas. Após 8 anos de EUA surgiu o desejo de possuir um negócio, e investindo em uma atividade que já conhecia (experiência familiar). Intuitivamente, vislumbrou uma crescente demanda na Flórida, por especialidades de padaria brasileira. Seu diferencial, em comparação com os concorrentes, seria as receitas brasileiras e o atendimento em português. Sua principal dificuldade, segundo relata, foram as restrições financeiras iniciais, por causa da construção e reforma das instalações, levando cinco anos para ele recuperar todo o investimento. Atualmente, ele tem um negócio bem sucedido, empregando 20 pessoas. Ele também acredita ter mais liberdade como empresário, mesmo trabalhando longas horas. Também disse que ele sempre teve muita ajuda de parentes e amigos para conseguir dinheiro: "eles me ajudaram a construir minha padaria nunca me cobraram nada". O empresário nunca considerou retornar ao Brasil, e considera a situação da sua pátria muito triste, mas acha que não se adaptaria.

O empreendedor "B" é um contador de 53 anos, que era empregado no Brasil antes de chegar aos EUA. Deixou o país por causa da paixão pelos EUA, apesar do fato de nunca ter estado lá. Em um ano desfez-se de tudo e saiu do Brasil com a família. Entraram no país com vistos de turista e sem qualquer expectativa de trabalho. Foram morar primeiro em Miami, mas depois se instalaram em Pompano Beach, onde seu irmão morava. Não era sua intenção empreender no começo. Demorou 14 anos antes de decidir abrir seu primeiro negócio nos EUA. Como contador, conhecia as leis e tributos locais, bem como as peculiaridades dos clientes, e, portanto, sentiu-se confiante em montar um plano de negócios. Primeiro trabalhou sozinho, mas hoje em dia emprega sete pessoas, sendo a maioria brasileira. Isso é importante pois sua clientela também é brasileira. Como teve baixo investimento inicial, o negócio se pagou rapidamente, após seis meses. Sua rede de amigos foi muito importante para o desenvolvimento do negócio, pois precisava de referências. Afirma que não retornaria mais ao Brasil, pois considera que seria difícil se adaptar e gostou do "modo de vida americano".

O empreendedor "C" veio para os EUA com uma função específica, prospecção de anunciantes para uma empresa de TV. Na chegada, ele teve problemas de comunicação, pois, de acordo com o empresário, seu conhecimento em inglês não era bom o suficiente para trabalhar nos EUA, o que levou à sua demissão após seis meses. Afirma que "conseguiu manter suas economias". Como era professor universitário e consultor no Brasil, decidiu abrir uma empresa de consultoria. Seu primeiro cliente foi um vendedor de carros que precisava de consultoria de marketing e treinamento de vendas. Desde então, ele nunca parou. Trabalhou como coach, sendo pioneiro nessa atividade na região. Através de suas palestras, tornou-se famoso na comunidade brasileira, envolvendo-se em programas de treinamento voltados somente para empresários brasileiros que queriam melhorar suas práticas de marketing, gerenciamento e vendas. Abriu o negócio para sobreviver, hoje seu negócio ainda é sua principal atividade. Para ele sua experiência no Brasil, tanto no varejo quanto no ensino,
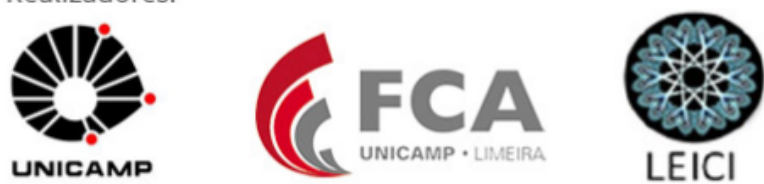
permitiu que ele combinasse a teoria e as práticas comerciais. Afirmou que seus amigos foram decisivos na abertura da empresa, ao indicá-lo para outros clientes e ajudá-lo com leis e impostos locais. Não teve nenhum treinamento específico prévio em sua atividade atual - um programa de treinamento lançado em 2010. Considera o mercado "difícil” e já pensou em desistir várias vezes.

A empreendedora " $D$ " é uma matemática que trabalhou como professora antes de decidir sair do Brasil. Decidiu morar nos Estados Unidos depois de uma visita ao namorado brasileiro que já se encontrava lá. Segundo ela, visitar os EUA influenciou-a fortemente na decisão de se mudar para lá. "Certamente, tive um choque de realidade, tendo uma visão totalmente diferente do país, diferente do que os brasileiros geralmente percebem". Ela queria se mudar para os EUA para oferecer a seus filhos melhores oportunidades de escolaridade, em uma sociedade menos violenta. Demorou seis meses para se mudar. No início decidiu se instalar sozinha antes de trazer as crianças, o que aconteceu apenas quatro anos após sua chegada. A empresária chegou sem saber falar inglês e sem perspectivas de trabalho. Estabeleceu-se em um bairro com uma significativa população de brasileiros instalada. Além da ajuda que teve de seus compatriotas, sentiu a necessidade de manter contato com sua comunidade étnica, já que muitos também não falavam inglês. Sua percepção indicava que muitos brasileiros estavam estagnados em suas posições de imigrantes, com poucas interações com a sociedade do país anfitrião. Talvez essa percepção fosse devido ao fato de viverem dentro do enclave étnico. Começou a trabalhar como governanta e faxineira, limpando lares, escritórios e um hotel, tanto para brasileiros quanto para americanos. Ao longo do tempo, seu trabalho foi reconhecido. Ela decidiu empreender, depois de ganhar experiência nessa atividade. A empresa chegou atualmente a quatro funcionários brasileiros, embora ofereça seus serviços exclusivamente aos americanos. Curiosamente, mesmo morando no seio da segunda maior concentração de brasileiros nos EUA, decidiu não servir a comunidade brasileira.

A empreendedora "E" é uma empresária que vive há mais de 17 anos nos EUA. Era assistente social e empresária no setor de vestuário no Brasil. Das várias razões para se mudar para os EUA, a empresária afirma que a crise econômica foi a decisiva. As questões culturais também foram levadas em consideração, como a corrupção, e a "desorganização social" que leva ao "modo brasileiro" de desordenar as coisas. A violência foi mencionada várias vezes na entrevista como um importante fator decisivo. Ela já conhecia os EUA, pois seu ex-marido era comissário de bordo de importante empresa brasileira do ramo de transporte aéreo e seu filho nasceu nos EUA quando morou temporariamente lá. Com seu marido atual, vendeu tudo no Brasil e chegou aos EUA, sem intenção de empreender. Depois de um tempo ela foi informada de que uma lavanderia em seu bairro estava prestes a falir, e estava à venda, assim, usaram suas economias e compraram esse negócio. Com a ajuda de amigos interessados em questões legais e fiscais, conseguiram seguir em frente. A loja passou a ser administrada de forma diferente dos antigos proprietários. Primeiro, os horários de atendimento ficaram bem

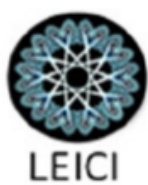


definidos. Em segundo lugar, eles procuraram melhorar a maneira como tratavam seus clientes. Segundo comentários de "E", "muitas empresas americanas são gerenciadas focando estritamente em fornecer o serviço, no entanto, às vezes deixam de lado um atendimento cordial". Segundo ela, isso se deve à alta demanda e volume de negócios da clientela. Sua estratégia, em oposição a isso, era de prestar mais atenção às pessoas. Essa foi certamente uma estratégia de sucesso, alcançando o retorno sobre o investimento após um ano.

Quando o empreendedor "F" chegou pela primeira vez para os EUA trabalhou por um tempo na Califórnia como empregado de uma empresa multinacional do ramo de tecnologia. Esse período foi decisivo para pensar em imigrar para os Estados Unidos. Segundo ele, "os imigrantes brasileiros, como quase todos os latino-americanos, seguem o dinheiro". Recentemente, ele percebeu uma mudança no perfil dos imigrantes atuais, dizendo que "Hoje percebo que o tipo de imigrante brasileiro que está chegando para os EUA é bastante diferente do que tivemos nos anos 80 e 90 . Naqueles dias, $90 \%$ eram aventureiros e $10 \%$ planejavam suas etapas. A maioria dos imigrantes queria correr riscos. Hoje, o que você vê é a maioria dos imigrantes que fogem da crise brasileira". Além disso, de acordo com o entrevistado, sua decisão de empreender nos EUA foi "precisamente por causa da não burocracia. Eu vi pessoas na Califórnia abrindo negócios e tendo todos os incentivos que não tínhamos no Brasil”. O empresário também citou estímulos do governo dos EUA para várias minorias, através da Small Business Administration [SBA]. Ele mostrou sinais de "não afiliação" com a cultura brasileira, falando que "até evito contanto com os brasileiros". Ele não voltaria ao Brasil porque não tem clientes brasileiros. O empresário com tristeza mencionou que toda vez que tentava vender algum projeto para qualquer agência do governo brasileiro, "alguém me chamava e dizia que queria $15 \%$, antes mesmo da negociação começar. (...) hoje, se você me disser que tem um excelente projeto para fazer com o Brasil, não estou interessado". Ele também ressalta: "todo mundo precisa gastar pelo menos um mês na Ásia ou na Alemanha para ver como eles realmente funcionam". O empreendedor decidiu se estabelecer em tecnologia da informação, principalmente porque ele "conhecia o mercado e tinha acesso a clientes e fornecedores. Ele também informou que depois de algum tempo de seu estabelecimento nos EUA, abriu escritórios em Hong Kong, Cingapura e Seul.

\section{Discussão dos casos}

Recordando que o objetivo do artigo era o de discutir as motivações que levam os empresários principais se concentrarem no enclave étnico ou no mercado local (ou global).

A região de Pompano Beach apresenta um conjunto robusto de empresas brasileiras, como observado pelos pesquisadores. Os empresários brasileiros que estão dispostos a operar dentro do enclave têm muitas vantagens competitivas, especialmente aqueles que buscam negócios

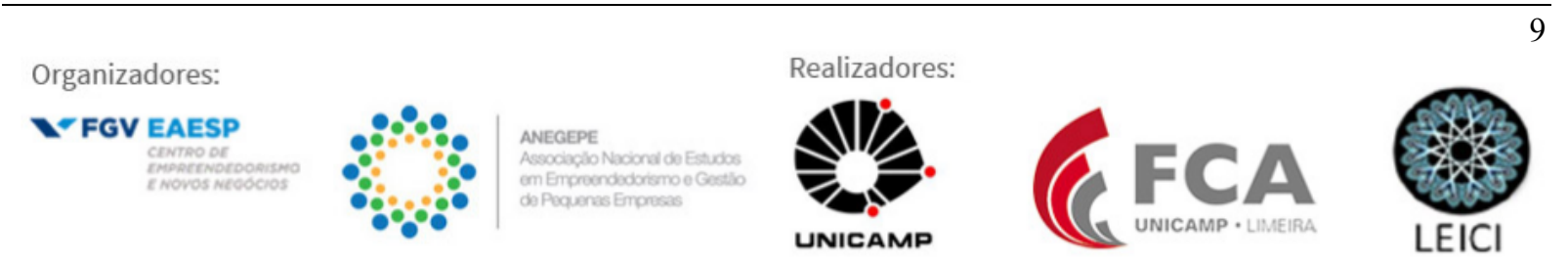


étnicos ou específicos. Os negócios atraem clientes que procuram restaurantes, lojas, remessas de dinheiro ou agências de viagens de estilo brasileiro (Cruz, Falcão, \& Barreto, 2017b).

As pequenas empresas bem-sucedidas dos empresários brasileiros no sul da Flórida parecem derivar de iniciativas conduzidas por indivíduos enérgicos que têm grande confiança pessoal ou que são propensos a arriscar. As observações dos autores apontaram inicialmente para três caminhos: (i) aqueles que entraram de forma irregular e não falavam inglês com fluência, no entanto, que estavam afiliados (ou ligados) às suas comunidades, optando por se concentrar no mercado do enclave; (ii) empresários que falavam inglês bem o suficiente para trabalharem, ou tiveram experiência executiva, gerando um distanciamento da cultura brasileira e maior afiliação à cultura americana. Esses empreendedores optaram por servir a população local e, portanto, estabeleceram-se fora do enclave; (iii) empreendedores que inicialmente foram ajudados por seus compatriotas, embora não tivessem nenhuma afiliação com a cultura, tentando distanciar-se de seus compatriotas.

O capital humano (Coleman, 1998), representado pela escolaridade ou proficiência em inglês, cria um maior acesso à oportunidades para aqueles que desejam se distanciar do enclave, a exemplo de "F", o empreendedor de tecnologia entrevistado, ou dos milhares de empreendedores de startups fundadas por imigrantes no Vale do Silício. Por exemplo: um executivo expatriado tem acesso a redes comerciais e fornecedores locais, já um imigrante, que não fala a língua, só tem acesso às redes de amigos e compatriotas dos enclaves, que acabam constituindo sua rede comercial. Os co-étnicos, repelindo sua própria cultura, passam por uma mistura de desconfiança, rejeição de valores e identificação com a cultura americana, como se vê nos relatos dos três empresários, que se concentram no público-alvo "fora do enclave". Além disso, Cruz, Falcão e Barreto (2017b) observaram um sentimento de "desconfiança limitada" entre os brasileiros em certos ambientes competitivos, como relatados na cidade de Orlando.

Ao observar os seis entrevistados, os pesquisadores perceberam em seus discursos, elementos que corroboravam com a literatura existente, como sua relação com os enclaves (afiliação x rejeição, rede de proteção), conexão com seus símbolos nacionais, e consumo de bens étnicos (ou não). Ao mesmo tempo, os empreendedores que enfocam no enclave demonstraram menos ressentimento em relação às oportunidades oferecidas no Brasil. Em seus discursos, é claro que a imigração representou, acima de tudo, novas oportunidades a serem exploradas, ao conseguirem superar as limitações estruturais de sua situação original (Shane \& Venkataraman, 2000). Os discursos também mostram empresários que desenvolveram um sentimento de rejeição sobre seus compatriotas brasileiros, desenvolvido ao longo de sua vivência no exterior. Também sugerem que aqueles que enfocam nos clientes fora do enclave podem ter maior capacidade de geração de empregos. As empresas cujo público-alvo eram os enclaves, geraram menos empregos, corroborando com Portes e Zhou (1992). Eles também têm custos de entrada relativamente baixos e retornos financeiros lentos a moderados, uma

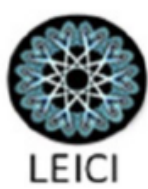


caracterização típica do impacto socioeconômico desse tipo de empreendedorismo (Summers, 2015). Dada a heterogeneidade dos perfis dos entrevistados, a contribuição desta análise reside na observação de elementos que não são freqüentemente explorados na literatura existente, a respeito dos ecossistemas empresariais norte-americanos - as relações complexas entre imigrantes e seus enclaves étnicos (Barkham \& Gudgin, 2002).

Três empresários já haviam trabalhado em empresas americanas. Assim, eles adquiriram experiências na mesma atividade que decidiram empreender e visaram criar uma "oferta de valor percebida" fora do enclave. Isso poderia evidenciar que trabalhar para empresas americanas poderia melhorar as redes locais e garantir a sobrevivência em um mercado mais amplo. Apenas um dos empresários comentou sobre a importância das organizações e associações locais na atividade empresarial, mas não pareceu beneficiar-se diretamente ou estar associado a nenhuma delas. Assim, a afiliação à organizações profissionais anteriores e a experiência comercial não agregam muito valor à análise (Barkham \& Gudgin, 2002).

Não há elementos para comparar crescimento e retorno entre empresas ou posicionamento, uma vez que a concorrência em cada indústria tem seu próprio arranjo de forças competitivas (Porter, 1989). O que realmente contribui para a discussão é o uso do enclave étnico (ou não) como um elemento de posicionamento nas várias estratégias adotadas, mesmo que inconscientemente (Roper, 1998). Cinco empresários ressaltaram a importância do apoio recebido de amigos brasileiros residentes nos EUA. Os mesmos cinco reivindicavam empregar predominantemente brasileiros em seus negócios. Empreendedor "F", da empresa transnacional de TI, declarou nenhuma afiliação com co-étnicos ou ter recebido qualquer benefício do enclave étnico. Ele enfatizou em seu relato as piores recordações do ambiente empresarial brasileiro. A empresária "E" afirmou que procurou distanciar-se da comunidade brasileira para melhor absorver a cultura local e dominar o inglês. Ressaltou que percebeu estagnação no convívio cultural onde inicialmente se inseriu dentro do enclave. Seu negócio também atende ao amplo mercado local, competindo fora do enclave étnico. Dois empresários que atendem ao mercado local sinalizaram, no entanto, que entendem que a incorporação de atenção individual e simpatia, características do povo brasileiro, eram um diferencial competitivo para seus negócios. Ambos reconhecem o apoio das comunidades brasileiras no início de sua experiência nos EUA e empregam brasileiros em seus negócios.

Três empresários atendem às necessidades do enclave étnico brasileiro nos EUA. Para eles, o enclave forneceu o acesso a clientes, sendo a própria base de seus negócios. As análises sugerem que o enclave étnico é importante mesmo para empresários que optaram por não atendê-lo diretamente, oferecendo uma rede de apoio inicial e fornecendo mão-de-obra necessária para realização das atividades, no início do negócio. No entanto, ao adotar o enclave como segmento-alvo, o empresário se apropria de uma reserva de mercado onde ele tem acesso privilegiado. Muitas vezes, este segmento do mercado pode apresentar demanda reprimida, oferecendo maiores oportunidades de crescimento do que a concorrência no

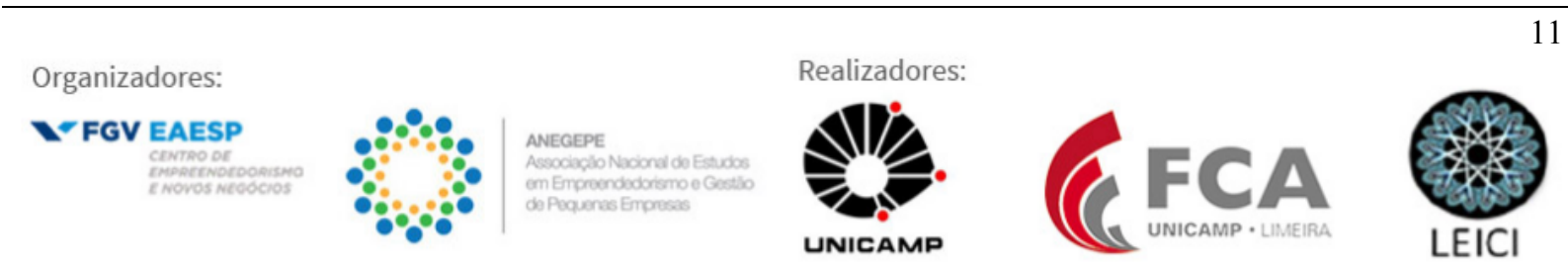


mercado amplo. Além disso, se alguém possui "habilidades étnicas", como dominar a língua, entender a cultura dos imigrantes ou saber como atendê-los, tudo isso pode se converter em vantagens competitivas, o que se apresenta de duas formas: (i) em acesso privilegiado aos estoques de trabalho, clientes e fornecedores, que são adequados para a realização de suas atividades; (ii) ao reforçar sua imagem e marca associadas à cultura brasileira (Barney, Hesterly, \& William 2011; Osterwalder, Pinho, Oliveira, \& Ferreira, 2011).

Oportunidades de negócio praticamente surgiram por indicações e referências de colegas compatriotas. Aparentemente, os entrevistados não se enxergavam como empreendedores, nem se sentiam capazes de empreender. Em relação a estrutura bifurcada proposta por Bögenhold (1987) e utilizada amplamente nas pesquisas do Global Entrepreneurship Monitor [GEM] (Herrington \& Kew, 2016), aparentemente o tipo dominante de empreendedorismo nas entrevistas foi o "motivado pela necessidade". Mesmo os empresários que alegaram ter alguma habilidade prévia nos negócios criados, apenas tomaram a iniciativa de fazê-lo devido à dificuldades de integração ao mercado formal de trabalho. As empresas surgiram de oportunidades circunstanciais, não planejadas. Como resultado disso, apenas um empreendedor afirmou que recebeu um investimento informal de um colega cidadão, dentro do enclave. Além disso, apenas um negócio declarou agir internacionalmente e ter a pretensão de crescimento. Os outros pareciam ter sua escala e capacidade já dimensionadas, com pouca perspectiva de expansão - típico de pequenas empresas.

Cinco empreendedores enfatizaram que o ato de empreender se deu devido à ausência de melhores opções. Apenas um afirmou que a empresa era interessante porque os EUA eram menos burocráticos, oferecendo melhor suporte para sua atividade. No entanto, este entrevistado não afirma claramente se sua intenção inicial era empreender. Portanto, a classificação empresarial que emerge dos relatos, na realidade, é o empreendedorismo por necessidade, o que pressupõe pouco planejamento e crescimento orgânico (Herrington \& Kew, 2016; Levie \& Autio, 2008).

A escolha da constituição de uma pequena empresa para a subsistência (empreendimento impulsionado pela necessidade) poderia ser explicada por um baixo nível de capital humano, possuído por parte dos imigrantes, indicando o conhecimento convencional dos estudos de "empreendedorismo imigrante" (Aldrich \& Waldinger, 1990). Esta situação, no entanto, não se aplica a todos os imigrantes. Estudos realizados na Flórida por Cruz, Barreto e Pinto (2015) apontam evidências significativas de que imigrantes altamente qualificados estão profissionalmente envolvidos em iniciativas empresariais. O mesmo acontece no Vale do Silício, com empreendedores iniciantes da nova economia (Chaganti, Watts, Chaganti, \& Zimmerman-Treichel, 2008). Os imigrantes com melhores níveis educacionais ou currículo profissional têm a possibilidade de se envolver em carreiras corporativas, superando os riscos do empreendedorismo (Becker, 1993). Por outro lado, os imigrantes cujo capital humano é menor, devido a terem acesso à menos oportunidades, decidem iniciar seus negócios para

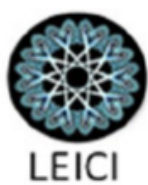


substituir um emprego formal (ou subemprego) de baixa remuneração. Nesse caso, os ganhos representados pela atividade empresarial superam os riscos.

Drori, Honig e Wright (2009) argumentam que os empresários "transnacionais" e "étnicos" podem tirar proveito de seu aproveitamento cultural relacionado ao seu capital social. À medida que interagem com os clientes em geral e se integram com as comunidades locais, eles podem ser capazes de decifrar o modus operandi das empresas locais. Portanto, eles podem ganhar vantagens competitivas, não dependendo mais de seus "clientes de nichos étnicos". Essa discussão apresenta-se resumida nas tabelas 2 e 3.

Tabela 2: Empreendedorismo por necessidade

\begin{tabular}{|c|c|c|c|}
\hline \multicolumn{2}{|r|}{ Dentro do Enclave } & \multicolumn{2}{|r|}{ Fora do Enclave } \\
\hline$R$ & $\begin{array}{l}\text { Não era um empresário no Brasil. Embora trabalhando para uma } \\
\text { empresa multinacional, ele era um funcionário da fábrica. Não } \\
\text { teve intenção inicial de empreende. Levou cinco anos para ele } \\
\text { recuperar seu investimento, com um sucesso gradual. } \\
\text { Não teve intencão inicial de empreender }\end{array}$ & D & $\begin{array}{l}\text { Chegou sem falar praticamente nenhum inglês e sem } \\
\text { oferta de trabalho. Decidiu se aventurar em serviços de } \\
\text { limpeza inicialmente para brasileiros e americanos, } \\
\text { trabalhando em um hotel também. Emprega } 4 \text { pessoas } \\
\text { principalmente brasileiras }\end{array}$ \\
\hline & \multirow{2}{*}{$\begin{array}{l}\text { Trabalhou no Brasil. Foi para os EUA para trabalhar, mas foi } \\
\text { demitido dentro de } 6 \text { meses devido ao inglês pobre. Abriu seus } \\
\text { negócios para a sobrevivência. Teve experiência profissional e } \\
\text { grau de ensino superior (professor universitário e consultor). } \\
\text { Emprega } 4 \text { pessoas em seus negócios. O investimento inicial foi } \\
\text { de US } \$ 30.000 \text {, devolvido dentro de três anos. Considera sua } \\
\text { empresa bem sucedida, embora se queixa um pouco sobre as } \\
\text { dificuldades atuais }\end{array}$} & E & $\begin{array}{l}\text { Sem querer, a empresária e seu marido, trabalharam } \\
\text { esporadicamente à medida que surgiram oportunidades. } \\
\text { Eles compraram um negócio existente. Recuperaram seu } \\
\text { investimento após apenas um ano. Contratam funcionários } \\
\text { de acordo com a sazonalidade da demanda. }\end{array}$ \\
\hline & & $\mathbf{F}$ & $\begin{array}{l}\text { "O imigrante brasileiro, como quase todos os latino- } \\
\text { americanos, vai atrás do dinheiro". }\end{array}$ \\
\hline
\end{tabular}

Tabela 3: Empreendedorismo por oportunidade

\begin{tabular}{|c|c|c|c|}
\hline \multicolumn{2}{|r|}{ Dentro do Enclave } & \multicolumn{2}{|r|}{ Fora do Enclave } \\
\hline A e C & Nenhuma evidência encontrada & De E & Nenhuma evidência encontrada \\
\hline B & $\begin{array}{l}\text { Estava empregado no Brasil. Tinha experiência } \\
\text { profissional e grau universitário. O sucesso de sua } \\
\text { empresa foi gradual e exigiu um baixo } \\
\text { investimento inicial, que fez o retorno sobre o } \\
\text { investimento para ser rápido, cerca de seis } \\
\text { meses. }\end{array}$ & $\mathbf{F}$ & $\begin{array}{l}\text { Trabalhou para uma empresa americana. Atualmente possui } \\
\text { escritórios em Hong Kong, Cingapura e Seul. É experiente. } \\
\text { Decidiu se estabelecer dentro do negócio de TI, porque "eu } \\
\text { conheci o mercado como eu acesso a clientes e } \\
\text { fornecedores". "Na verdade, o que era mais difícil para mim } \\
\text { no momento, era escolher o tipo de cliente para atender". }\end{array}$ \\
\hline
\end{tabular}

De acordo com evidências coletadas, a motivação para empreender dos entrevistados é basicamente orientada para a necessidade, não fazendo muita distinção entre o foco no enclave ou não. Os empreendedores que visam o enclave parecem ser mais dependentes do seu ecossistema, incluindo sua rede de amigos, clientes e fornecedores. Eles se beneficiam de sua interação de contato com os compatriotas para contratação de funcionários. Embora existam evidências de relacionamento empreendedor dentro do enclave por parte dos empreendedores que atuam fora dele, eles enfatizam, por meio de seus discursos, que essas relações englobam um caráter pessoal e geralmente ocorrem em uma fase inicial de seu estabelecimento no país anfitrião (vide tabelas 4 e 5).

Tabela 4: Relações empresariais dentro do enclave

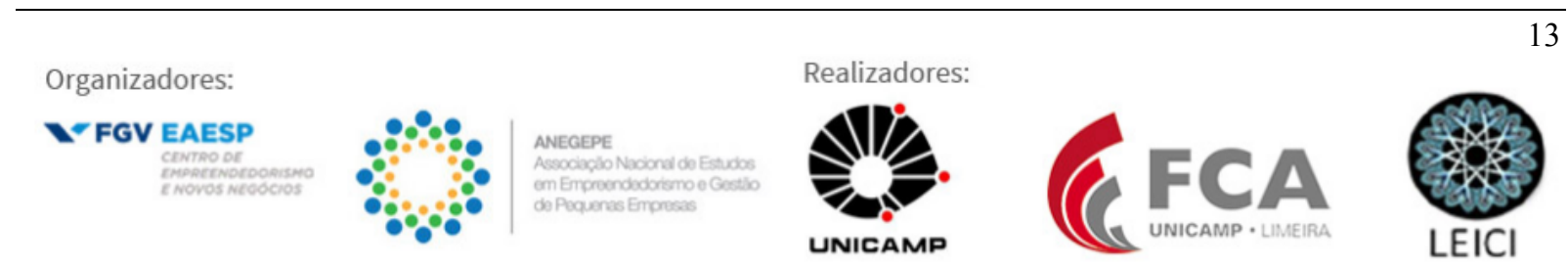




\begin{tabular}{c|l|l|l}
\hline \multicolumn{1}{c|}{ Dentro do Enclave } & \multicolumn{2}{c}{ Fora do Enclave } \\
\hline A & $\begin{array}{l}\text { Foi apoiado por uma rede de amigos. Observou a demanda dos } \\
\text { brasileiros no local. Seus principais diferenciais foram receitas e } \\
\text { serviços brasileiros em português. Contratou funcionários brasileiros }\end{array}$ & D & $\begin{array}{l}\text { Estabeleceu-se em um bairro majoritário brasileiro. } \\
\text { Contratou funcionários brasileiros }\end{array}$ \\
\hline B & $\begin{array}{l}\text { Foi apoiado por uma rede de amigos. Contratou funcionários } \\
\text { brasileiros }\end{array}$ & E & $\begin{array}{l}\text { No início, ela morava com amigos. Obteve suas } \\
\text { primeiras oportunidades de trabalho através de amigos } \\
\text { brasileiros e suas referências }\end{array}$ \\
\hline C & $\begin{array}{l}\text { Foi apoiado pela rede de amigos. Atualmente emprega 20 pessoas } \\
\text { (muitos brasileiros). Seu negócio tem como objetivo ajudar os os } \\
\text { brasileiros a abrir seus negócios na Flórida. A maioria dos seus } \\
\text { clientes não domina a língua inglesa ou não tem um diploma } \\
\text { universitário ou universitário. }\end{array}$ & F & Nenhuma evidência encontrada \\
\hline
\end{tabular}

Tabela 5: Relações empresariais fora do enclave

\begin{tabular}{c|c|c|l}
\hline \multicolumn{2}{c|}{ Dentro do Enclave } & \multicolumn{2}{c}{ Fora do Enclave } \\
\hline \multirow{2}{*}{ A } & \multirow{2}{*}{$\begin{array}{c}\text { Nenhuma } \\
\text { evidência }\end{array}$} & D & $\begin{array}{l}\text { Não sentiu necessidade de manter contato com as comunidades brasileiras, já que muitos de seus } \\
\text { compatriotas não falavam inglês. Servindo exclusivamente aos locais }\end{array}$ \\
\cline { 4 - 4 } \begin{tabular}{c} 
encontrada. \\
\cline { 3 - 4 } B
\end{tabular} & E & Decidiu viver como americana. "Me mudei para viver como americano". Atende qualquer cliente \\
\cline { 3 - 4 } & F & Ele não é afiliado e evita a cultura brasileira / nacionais. Ele não possui clientes brasileiros e nunca teve \\
\hline
\end{tabular}

A falta de evidências de ação fora do enclave novamente aponta para a dependência do ecossistema do enclave, mostrado na tabela 5. É interessante notar que todos os empresários que trabalham para os clientes do mercado local, em geral mostram certo medo ou desconfiança em manterem relacionamentos com os brasileiros.

De todos os entrevistados, apenas um deles não possuía diploma universitário. No entanto, ele foi inserido no mercado de trabalho quando decidiu sair do Brasil. Portanto, a ausência de oportunidades estava ligada a uma maior variedade de fatores do que simplesmente sobrevivência, escapando do estigma de baixa capacitação dos emigrantes latino-americanos.

Os empresários brasileiros, que atendem ao mercado local, geralmente possuem relações comerciais pré-estabelecidas com fornecedores locais e clientes. Às vezes, isso é devido a falta de afiliação cultural, ou um sentimento de rejeição em relação às suas comunidades étnicas, chamado "desconfiança limitada" (Cruz, Falcão e Barreto, 2017b). Neste contexto, o empresário estará sujeito às forças do mercado de Porter (1989), enfrentando uma concorrência maior. Para desempenharem bem no mercado local, eles devem ser bem aculturados ao ambiente americano, falar inglês fluentemente, ou já ter trabalhado em empresas (não étnicas) ou estudado no país. Trabalhar voltado para a segmentação étnica pode beneficiar aqueles que sabem lidar com as especificidades culturais. $\mathrm{Na}$ tabela 6 apresenta-se um resumo dos achados relativos à afiliação à cultura americana.

Tabela 6: Afiliação do empreendedor à cultura americana

\begin{tabular}{|c|c|c|c|}
\hline \multicolumn{2}{|c|}{ Dentro do Enclave } & \multicolumn{2}{|r|}{ Fora do Enclave } \\
\hline & & D & Vive há mais de 14 anos nos EUA \\
\hline $\begin{array}{l}\text { A } \\
\mathrm{e} \\
\mathrm{B}\end{array}$ & $\begin{array}{c}\text { Apaixonado pelos } \\
\text { EUA }\end{array}$ & $E$ & $\begin{array}{l}\text { Descobriu "outro país". Decidiu oferecer a seus filhos melhores oportunidades para estudar em uma } \\
\text { sociedade menos violenta e com muitas oportunidades. Instalada após seis meses, mas apenas } \\
\text { trouxe seus filhos quatro anos após sua chegada. Queria se afastar de estímulos culturais ou notícias } \\
\text { do Brasil }\end{array}$ \\
\hline
\end{tabular}
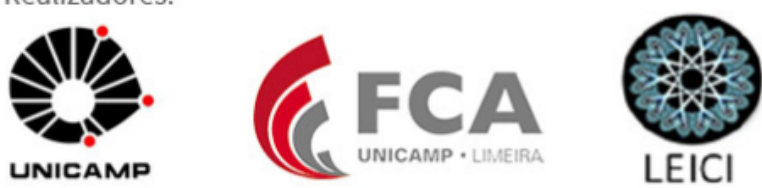
C

\begin{tabular}{|l|l|l|l}
\hline $\begin{array}{l}\text { Vive há mais de 14 } \\
\text { anos nos EUA }\end{array}$ & $\mathbf{F}$ & $\begin{array}{l}\text { Ex-esposa de um comissário da linha aérea brasileira, tendo viajado para os Estados Unidos várias } \\
\text { vezes. Morava na Califórnia durante o período em que seu ex-marido voou de Los Angeles X Tóquio. } \\
\text { Seu filho mais novo (agora com } 46 \text { anos) nasceu nos EUA. Mora nos EUA há mais de 17 anos. } \\
\text { Conheceu Miami em uma viagem de férias cujo objetivo era encontrar um lugar para se mover } \\
\text { definitivamente. Postula que todos deveriam ter uma maneira humanizada de servir os clientes. }\end{array}$ \\
\hline
\end{tabular}

Quem trabalha dentro do enclave parece manter uma "relação platônica" com a cultura americana - eles adoram o "american way of life" à distância. Declaram se sentir bem no país, mas ainda estão mais conectados aos seus próprios compatriotas; portanto, eles se relacionam com os brasileiros e não com os americanos. Um ditado bem conhecido entre os brasileiros que vivem na Flórida pode reforçar isso: "A Flórida é o Brasil que funciona". Esta frase demonstra certo "apego" aos elementos nacionais que ainda os cercam, como o clima semelhante, a latinidade e, principalmente, o ambiente social "brasileiro" do enclave e os produtos étnicos amplamente disponíveis lá. Por outro lado, os empresários que visam os clientes em geral, demonstram que estão particularmente bem aculturados enquanto vivem na América como americanos reais (vide tabela 7).

Tabela 7: Afiliação do empreendedor à cultura brasileira

\begin{tabular}{c|l|c|l}
\hline \multicolumn{2}{c}{ Dentro do Enclave } & \multicolumn{2}{c}{ Fora do Enclave } \\
\hline A & $\begin{array}{l}\text { Decidiu se mudar para a Flórida, por parecer mais com o Brasil. Não } \\
\text { retornaria ao Brasil, considerando que seu "país está passando por } \\
\text { uma situação muito triste", então ele acredita que ele não se adaptará } \\
\text { mais ao Brasil. }\end{array}$ & Nenhuma evidência encontrada \\
\hline B & $\begin{array}{l}\text { Atende às igrejas brasileiras. "Há um parque perto daqui, onde eu } \\
\text { saio com muitos brasileiros, é quase como um clube". }\end{array}$ & E & $\begin{array}{l}\text { Usa seu "caminho brasileiro" e simpatia como um } \\
\text { diferencial competitivo para servir os locais }\end{array}$ \\
\hline C & "Eu viajo para o Brasil todos os anos" & F & Nenhuma evidência encontrada \\
\hline
\end{tabular}

A literatura seminal existente sobre o empreendedorismo imigrante mostra que os empresários que trabalham com o enclave mantêm fortes laços culturais com seu país de origem (por exemplo, Portes \& Zhou, 1992; Rath \& Kloosterman, 2000). Apesar de não terem relatos de casos de empresários que rejeitam sua própria cultura, os trabalhos sobre o empreendedorismo étnico (ligados à segunda e terceira geração de imigrantes) apontam para o surgimento de fenômenos deste tipo (Aldrich \& Waldinger, 1990; Barret, Jones e McEvoy, 1996; Xie \& Gough, 2011). O que é particularmente curioso, no caso dos empresários brasileiros, é a rejeição de sua própria cultura (e valores), entre aqueles que acabaram de imigrar. Isso pode estar relacionado com os motivos da imigração, que no caso dos brasileiros se referem principalmente a um sentimento de exaustão ou fadiga com as instituições brasileiras (Cruz, Falcão e Barreto, 2017b). Por exemplo, o Empreendedor "E" apontou que os principais motivos de sua emigração foram "fatores relacionados à sua situação econômica, questões culturais, desorganização social que leva ao ambiente brasileiro, violência, etc." No entanto, o empreendedor "F", aponta que "nunca voltaria ao Brasil!" Portanto, ficou claro que ele não é afiliado aos brasileiros e ainda evita a cultura brasileira, ao mencionar: "Eu repudio a
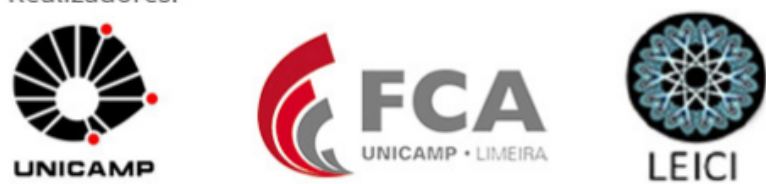
corrupção em todos os níveis, incluindo corrupção corporativa". Além disso, mencione que: "hoje em dia, se você me disser que ... tem um excelente projeto no Brasil, não vou aceitar".

\section{Considerações finais}

O objetivo do artigo foi o de discutir fatores que levam os empreendedores ou a enfocarem no enclave étnico ou nos mercados locais (ou globais). Imigrantes brasileiros, provenientes de um ambiente predominantemente orientado para a necessidade, são "contaminados" por um ecossistema impulsionado pela inovação, ao chegarem nos EUA.

$\mathrm{O}$ artigo mostra sua relevância teórica em três aspectos. Primeiro, combinando questões relevantes dentro de diferentes teorias do empreendedorismo, a saber: a teoria do empreendedorismo geral, o empreendedorismo étnico e imigrante, o perfil do empreendedor e o ecossistema empresarial. Em segundo lugar, ele lança luz sobre ao fenômeno da imigração, que tem ganho atenção devido à sua intensificação em escala mundial. Em terceiro lugar, observa-se uma minoria étnica no contexto de um país desenvolvido.

Além disso, as implicações teóricas do artigo estão relacionadas a sua contribuição para o conhecimento a respeito do empreendedorismo imigrante e/ou étnico. Os autores examinam três dimensões de sua interação: (i) a relação entre empresários imigrantes e outros imigrantes (enclave étnico), (ii) sua afiliação cultural, representada pela relação entre empresários imigrantes e comunidades locais, e (iii) relação entre empreendedorismo tipos de orientação (oportunidade ou necessidade) para sua escolha de público-alvo (enclave étnico ou clientes locais). As implicações gerenciais do artigo incluem idéias para futuros empreendedores de contextos similares, assim como responsáveis por estabelecer políticas públicas dirigidas a empresários imigrantes ou étnicos.

As limitações do trabalho são inerentes ao seu método, especialmente derivadas do número de entrevistados selecionados e pela subjetividade de uma análise qualitativa. Embora esta abordagem metodológica não permita generalizações estatísticas, ela contribui para uma abordagem exploratória do fenômeno, apresentando respaldo teórico. Como sugestão para estudos futuros sugere-se a observação dos mesmos elementos em comunidades de imigrantes brasileiras (ou outras) de diferentes países anfitriões, permitindo comparações e aprofundamento da teoria. Empregando uma abordagem quantitativa, e estabelecendo-se uma amostra robusta de empresários imigrantes, pode-se esperar uma generalização dos achados.

\section{Referências}

Aldrich, H. E., \& Waldinger, R. (1990). Ethnicity and entrepreneurship. Annual review of sociology, 16(1), 111-135.

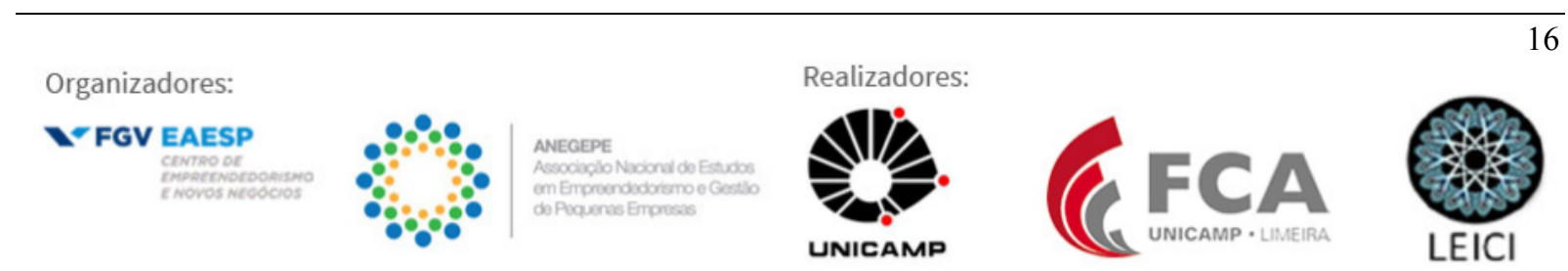


Barkham, R., \& Gudgin, G. (2002). Determinants of small firm growth: An inter-regional study in the United Kingdom 1986-90(Vol. 12). Psychology Press.

Barney, J., Wright, M., \& Ketchen Jr, D. J. (2001). The resource-based view of the firm: Ten years after 1991. Journal of Management, 27(6), 625-641.

Barrett, G. A., Jones, T. P., \& McEvoy, D. (1996). Ethnic minority business: Theoretical discourse in Britain and North America. Urban studies, 33(4-5), 783-809.

Becker, G. S. (1993). Nobel lecture: The economic way of looking at behavior. Journal of political economy, 101(3), 385-409.

Bögenhold, D. (1987), De Gründerboom: Realität und Mythos der neuenSelbständigkeit, Campus, Frankfurt.

Bolton, B. K., \& Thompson, J. (2004). Entrepreneurs: Talent, temperament, technique. Routledge.

Bourdieu, P. (1986). The forms of capital Handbook of theory and research for the sociology of education (pp. 241-258). R.(1974). The Power Broker: Robert Moses and the Fall of NY.

Burns, P. (2001). Entrepreneurship and Small Business, Palgrave, Basingstoke.

Carter, S. (2000). Gender and Enterprise. In Enterprise and Small Business: Principles, Practice and Policy, edited by S. Carter. and D. Jones-Evans. Harlow: Prentice Hall/Pearson Education Limited.

Casson, M., \& Wadeson, N. (2007). The discovery of opportunities: Extending the economic theory of the entrepreneur. Small Business Economics, 28(4), 285-300.

Castells, M., \& Portes, A. (1989). World underneath: The origins, dynamics, and effects of the informal economy. The informal economy: Studies in advanced and less developed countries, 12.

Chaganti, R. R. S., Watts, A. D., Chaganti, R., \& Zimmerman-Treichel, M. (2008). Ethnicimmigrants in founding teams: Effects on prospector strategy and performance in new Internet ventures. Journal of Business Venturing, 23(1), 113-139.

Coleman, J. S. (1988). Social capital in the creation of human capital. American journal of sociology, 94, S95-S120.

Companys, Y. E., \& McMullen, J. S. (2007). Strategic entrepreneurs at work: the nature, discovery and exploitation of entrepreneurial opportunities, Small Business Economics, Vol 28, No 4, pp 301-322

Creswell, J. W. (2013). Research design: Qualitative, quantitative, and mixed methods approaches. Sagepublications.

Cruz, E. P., Barreto, C. R., \& Pinto, C. B. (2015). Internationalization of Small Business: An Investigation about Brazilian Business in Orlando City. Journal of Management Policy and Practice, 16(3), 78.

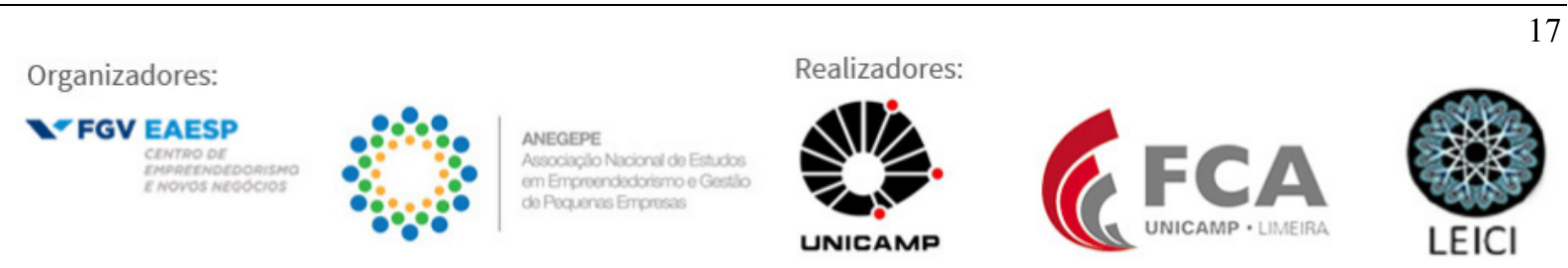


Cruz, E. P., Falcão, R. P. D. Q., \& Barreto, C. R. (2017a). Estudo exploratório do empreendedorismo imigrante brasileiro em Pompano Beach e Orlando - EUA. Gestão \& Planejamento-G\&P, 18.

Cruz, E. P., Falcão, R. P. de Q., \& Barreto, C. R. (2017b). Immigrant entrepreneurship: a study on Brazilian businesses at Pompano Beach-Florida. In United States Association for Small Business and Entrepreneurship. Conference Proceedings (p. 41). United States Association for Small Business and Entrepreneurship.

Denzin, N. K., \& Lincoln, Y. S. (Eds.). (2011). The Sage handbook of qualitative research. Sage.

Douglas, E. J., \& Shepherd, D. A. (2002). Self-employment as a career choice: Attitudes, entrepreneurial intentions, and utility maximization. Entrepreneurship theory and practice, 26(3), 81-90.

Drori, I., Honig, B., \& Wright, M. (2009). Transnational entrepreneurship: An emergent field of study. Entrepreneurship Theory and Practice, 33(5), 1001-1022.

Eisenhardt, K. M. (1989). Agency theory: An assessment and review. Academyof management review, 14(1), 57-74.

Filion, L. J. (2011). Defining the entrepreneur. World encyclopedia of entrepreneurship, 41.

Gordon, M. M. (1961). Assimilation in America: Theory and reality. Daedalus, 90(2), 263285.

Herrington, Mike; Kew, Penny. (2016). “Global Report 2016/2017”. GEM - Global Entrepreneurship Monitor, 1-180.

Knight, G. (1996). Born global. Wiley International Encyclopedia of Marketing.

Levie, J., \&Autio, E. (2008). A theoretical grounding and test of the GEM model. Small Business Economics, 31(3), 235-263.

Osterwalder, A., Pigneur, Y., Oliveira, M. A. Y., \& Ferreira, J. J. P. (2011). Business Model Generation: A handbook for visionaries, game changers and challengers. African journal of business management, 5(7), 22-30.

Porter, M. E. (1989). From competitive advantage to corporate strategy. In Readings in strategic management (pp. 234-255). Macmillan Education UK.

Portes, A. (1997). Globalization from below: the rise of transnational communities. The ends of globalization: bringing society back in, 253-70.Princeton University: WPTC-98-01.

Portes, A., \& Sensenbrenner, J. (1993). Embeddedness and immigration: Notes on the social determinants of economic action. American journal of sociology, 98(6), 1320-1350.

Portes, A., \& Zhou, M. (1992). Gaining the upper hand: Economic mobility among immigrant and domestic minorities. Ethnic and racial studies, 15(4), 491-522.

Rath, J., \& Kloosterman, R. (2000). Outsiders' business: A critical review of research on immigrant entrepreneurship. International Migration Review, 657-681.

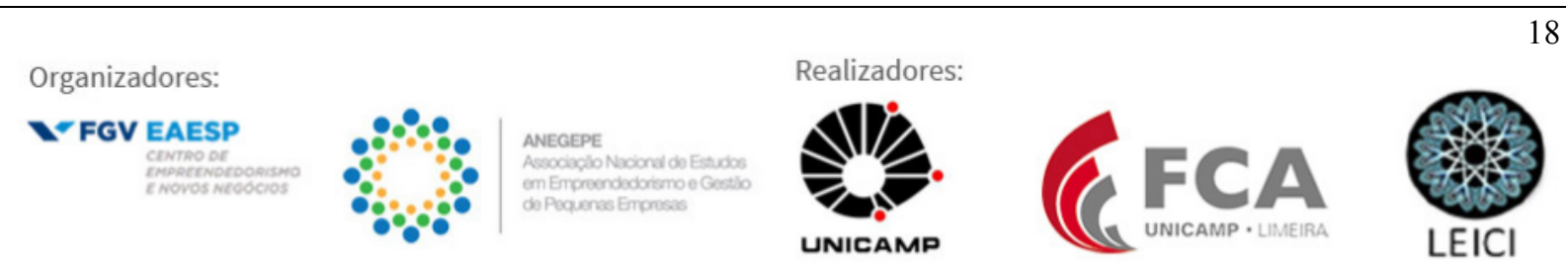


Roper, S. (1998). Entrepreneurial characteristics, strategic choice and small business performance. Small Business Economics, 11(1), 11-24.

Sales, T. (1999). Brasileiros longe de casa. Cortez Editora.

Saxenian, A. (1999). Silicon Valley's New Immigrant Entrepreneurs. San Francisco: Public Policy Institute of California.

Shane, S., \& Venkataraman, S. (2000). The promise of entrepreneurship as a field of research. Academy of management review, 25(1), 217-226.

Summers, D. (2015). The Economic Impact of Entrepreneurship. Academy of Entrepreneurship Journal, 21(2), 99-108.

Waldinger, R. (1993). The ethnic enclave debate revisited. International journal of urban and regional research, 17(3), 444-452.

Williams, C. C. (2009). The motives of off-the-books entrepreneurs: necessity-or opportunitydriven? International Entrepreneurship and Management Journal, 5(2), 203.

Xie, Y., \& Gough, M. (2011). Ethnic enclaves and the earnings of immigrants. Demography, 48(4), 1293-1315.

Zhou, M. (2004). Revisiting ethnic entrepreneurship: convergencies, controversies, and conceptual advancements. International migration review, 38(3), 1040-1074. 